\title{
Is remote rehabilitation after stroke as effective as conventional therapy?
}

Can Ozan Tan, PhD

Neurology ${ }^{\circledR}$ 2020;95:e2462-e2464. doi:10.1212/WNL.0000000000010839

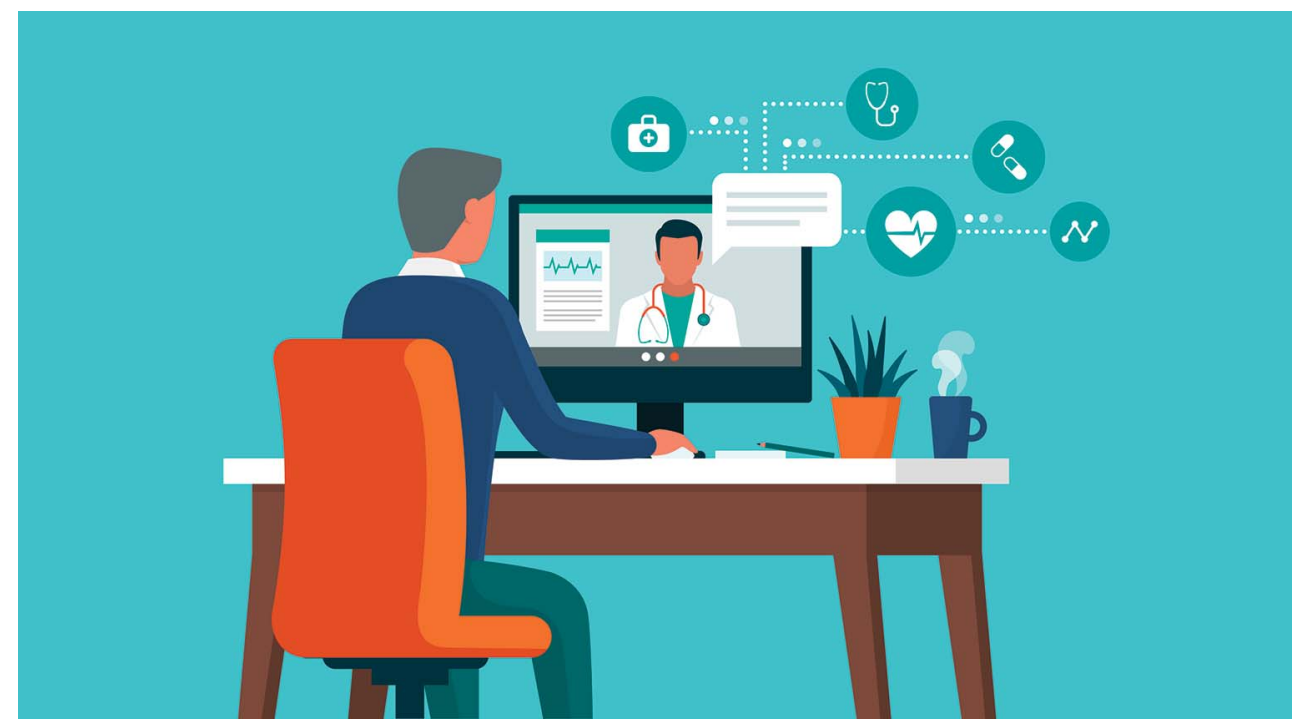

Related Article

Effects of home-based telerehabilitation in patients with stroke: A randomized controlled trial

http://dx.doi.org/10.1212/ WNL.0000000000010821

Stroke is a frightening experience that may have a large impact on daily activities. Over half of the survivors are left unable to move their affected leg, arm, or fingers. After 6 months, many still require some level of assistance. But the brain is a remarkable organ. Regular physical and cognitive activity can improve parts of the brain that have been injured. Stroke rehabilitation relies on this ability and helps the brain relearn skills that were initially lost. Thus, effective rehabilitation is key for stroke survivors to regain or improve their ability to carry out usual daily activities.

Stroke rehabilitation starts during the initial hospital stay and continues after discharge, guided by a physician and other professionals. Rehabilitation is not always completed. One possible cause is reduced ability to have in-person contact (as during the COVID-19 pandemic). A shortage of rehabilitation clinics and transportation problems are other causes. In such cases, telehealth services (defined as health care that is provided remotely using telecommunications technology) provide an alternative to typical rehabilitation to ensure continuation of effective care.

Telerehabilitation, or the remote delivery of rehabilitation care, has a relatively short history. ${ }^{1}$ Because of this, many patients are uncertain whether it will be effective. However, the past 5 years have seen much new research that has improved the effectiveness of telerehabilitation. In this issue of Neurology ${ }^{\circledR}$, Chen et al. ${ }^{2}$ contribute to this body of research. They report the results of a small trial on the effectiveness of telerehabilitation in improving arm and leg function after a stroke.

\section{What did the investigators find?}

In this study, investigators randomly (as with a coin toss) assigned 26 people who recently experienced a stroke to receive typical in-person rehabilitation at an outpatient clinic. They assigned another 26 patients to participate in telerehabilitation via live videoconferencing with a therapist. Both programs aimed for up to 10 rehabilitation sessions. Each session included 1 hour of occupational and physical therapy. Investigators then looked at physical function, balance, sensation, and joint function in the arms and legs. They also assessed the 
patients' ability to independently carry out everyday activities before and after rehabilitation. They used brain scans to assess the effect of rehabilitation on brain function.

At the end of treatment for both patient groups, the investigators found no difference between in-person therapy and telerehabilitation for physical function and independence. Similarly, no differences were seen in brain structure and function.

\section{What does this mean?}

When considered with earlier studies, ${ }^{3,4}$ results from this trial show that stroke telerehabilitation is a safe and effective alternative to typical in-person rehabilitation clinics.

\section{What remains unknown?}

As with any other research, this trial has limitations. First, only a small number of people were studied (52 in total). These results need to be verified in a larger group of patients.

Second, those who were assigned to telerehabilitation spent approximately $10 \%$ more time in rehabilitation compared to those who received in-person therapy. It is unclear whether the 2 types of treatment would still offer equal benefits if both included the same amount of therapy. Overall, this work still shows that telerehabilitation may improve access to care.

Third, we know that the odds of improvement and degree of improvement depend on the type and severity of stroke. Chen and colleagues ${ }^{2}$ focused on a specific type of stroke and did not consider differences in severity. Therefore, it is difficult to determine whether the results would hold for all stroke survivors.

Fourth, conditions that existed before the stroke (such as joint pain or heart disease) and those that can develop after (such as pain or depression) can change the effectiveness of rehabilitation. It is unknown whether these conditions impact different types of rehabilitation the same way.

Finally, Chen et al. ${ }^{2}$ focused on physical function. Whether telerehabilitation is similarly effective for improving thinking and language abilities after a stroke remains unknown.

Despite its limitations, the current study provides important evidence supporting the effectiveness of poststroke care using telerehabilitation. 


\section{About stroke}

Adapted from Rewinkel S. Regular sauna use shown to decrease risk of first-time stroke. Neurology 2018;90: e2014-e2016.

\section{What is stroke?}

There are 2 kinds of stroke. In the first type, called ischemic stroke, there is loss of blood flow to a certain part of the brain. About $85 \%$ of all strokes are ischemic. Often this is caused by a blockage in a blood vessel. When blocked, blood and oxygen cannot get to the area of brain that the blood vessel supplies. If this goes on long enough, the brain cells begin to die. Ischemic stroke can be caused by narrowing of the large arteries to the brain, also known as atherosclerosis. In other people, a clot can form in arteries of the neck. If a piece of the clot breaks off, it can travel to the brain and block a brain blood vessel. In the same way, clots may also form in the heart, and travel by blood flow to the brain vessels, causing stroke.

In the second type of stroke, bleeding occurs into the brain: this is called a hemorrhagic stroke. Bleeding may occur for several reasons. In one type, an aneurysm, which is a weakened blood vessel, breaks open or ruptures. When this happens, the bleeding puts pressure on surrounding brain. The pressure injures and possibly kills the nearby brain cells.

In either type of stroke, the resulting brain damage may cause weakness, numbness, and speech problems. If the stroke is severe enough, it can lead to coma, and possibly death.

There are effective ways to prevent stroke. When having a stroke, seeking immediate medical attention can help reduce chances of death and disability.

\section{How common is stroke?}

Every year, about 800,000 people in the United States have a stroke. Stroke is the nation's number 3 killer, after heart disease and cancer, and the number 1 cause of adult disability. In the United States, Black patients are at greatest risk for stroke compared to other races.

Transient ischemic attacks, or TIAs, have many similarities with strokes. TIAs occur when a clot temporarily blocks a blood vessel, resulting in symptoms much like those of a stroke. However, the symptoms of a TIA last less than 24 hours and there is no permanent brain damage. TIA can be a warning sign for a later stroke.

\section{Treatment of stroke}

There are many treatments for strokes. Treatment selection depends on whether the stroke is ischemic or hemorrhagic. A picture of the brain, such as a CT or MRI scan, is usually performed to determine the type of stroke. Once a doctor determines whether the stroke is ischemic or hemorrhagic, treatment can begin.

Ischemic stroke, if identified early, can be treated with tissue plasminogen activator (tPA), a medication that breaks down the clot blocking the blood vessel in the brain. tPA is only effective if given within hours of stroke onset. This is one reason why the time of onset of the stroke is so important to remember.

Treatment of hemorrhagic stroke is very different from that of ischemic stroke. The treatment of hemorrhagic stroke depends on the cause of the bleeding and how much bleeding has occurred. Some hemorrhagic strokes require treatment by a surgeon.

\section{Prevention is the key}

There are many risk factors for stroke. Some risk factors for stroke cannot be prevented. We cannot change our age, race, or family history of stroke. However, we can address risk factors like high blood pressure, an irregular heart rate (like atrial fibrillation), diabetes, cigarette smoking, high cholesterol (and fat levels in the bloodstream), alcohol abuse, and obesity. Treatment is available for all of these risk factors, and appropriate treatment can substantially reduce risk of stroke.

For more information

Brain \& Life

brainandlife.org

\section{National Institute of Neurologic Disorders and Stroke \\ ninds.nih.gov/}

\section{American Stroke Association \\ stroke.org/}

\section{References}

1. Rose FD, Brooks BM, Rizzo AA. Virtual reality in brain damage rehabilitation: review. Cyberpsychol Behav 2005; 8:241-271

2. Chen J, Sun D, Zhang S, et al. The effects of home-based telerehabilitation in patients with stroke: a randomized controlled trial. Neurology 2020;95:e2318-e2330.

3. Laver KE, Adey-Wakeling Z, Crotty M, Lannin NA, George S, Sherrington C. Telerehabilitation services for stroke. Cochrane Database Syst Rev 2020;1:CD010255.

4. Sarfo FS, Ulasavets U, Opare-Sem OK, Ovbiagele B. Tele-rehabilitation after stroke: an updated systematic review of the literature. J Stroke Cerebrovasc Dis 2018;27: 2306-2318. 


\section{Neurology}

\section{Is remote rehabilitation after stroke as effective as conventional therapy? \\ Can Ozan Tan \\ Neurology 2020;95;e2462-e2464 \\ DOI 10.1212/WNL.0000000000010839}

This information is current as of October 26, 2020

Updated Information \& Services

References

Permissions \& Licensing

Reprints including high resolution figures, can be found at: http://n.neurology.org/content/95/17/e2462.full

This article cites 4 articles, 1 of which you can access for free at: http://n.neurology.org/content/95/17/e2462.full\#ref-list-1

Information about reproducing this article in parts (figures,tables) or in its entirety can be found online at:

http://www.neurology.org/about/about_the_journal\#permissions

Information about ordering reprints can be found online:

http://n.neurology.org/subscribers/advertise

Neurology ${ }^{\circledR}$ is the official journal of the American Academy of Neurology. Published continuously since 1951, it is now a weekly with 48 issues per year. Copyright (O) 2020 American Academy of Neurology. All rights reserved. Print ISSN: 0028-3878. Online ISSN: 1526-632X.

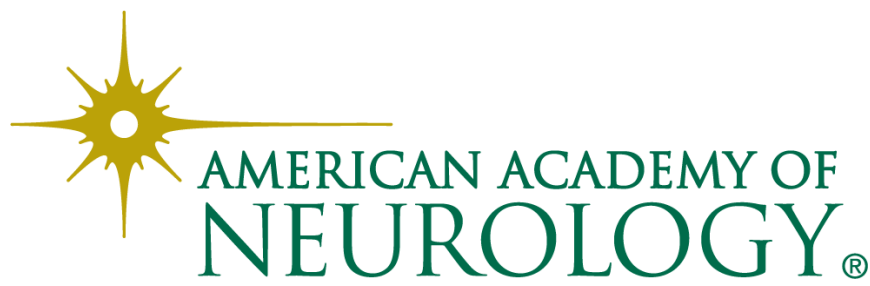

